\title{
Risk of rhabdomyolysis with donepezil compared with rivastigmine or galantamine: a population-based cohort study
}

\author{
Jamie L. Fleet MD, Eric McArthur MSc, Aakil Patel, Matthew A. Weir MSc MD, Manuel Montero-Odasso MD PhD, \\ Amit X. Garg MD PhD
}

Cite as: CMAJ 2019 September 16;191:E1018-24. doi: 10.1503/cmaj.190337

\begin{abstract}
BACKGROUND: Donepezil, rivastigmine and galantamine are popular cholinesterase inhibitors used to manage the symptoms of Alzheimer disease and other dementias; regulatory agencies in several countries warn about a possible risk of rhabdomyolysis with donepezil, based on information from case reports. Our goal was to investigate the 30-day risk of admission to hospital with rhabdomyolysis associated with initiating donepezil versus other cholinesterase inhibitors.
\end{abstract}

METHODS: We conducted a retrospective cohort study in Ontario, Canada, from 2002 to 2017. Participants were adults aged 66 years or older with a newly dis- pensed prescription for donepezil compared with rivastigmine or galantamine. The primary outcome was hospital admission with rhabdomyolysis (assessed using hospital diagnostic codes) within 30 days of a new prescription of a cholinesterase inhibitor. Odds ratios were estimated using logistic regression, with inverse probability of treatment weights calculated from propensity scores.

RESULTS: The average age in our 2 groups was 81.1 years, and $61.4 \%$ of our population was female. Donepezil was associated with a higher risk of hospital admission with rhabdomyolysis compared with rivastigmine or galantamine (88 events in
152300 patients [0.06\%] v. 16 events in 68053 patients [0.02\%]; weighted odds ratio of $2.21,95 \%$ confidence interval [Cl] 1.52-3.22). Most hospital admissions with rhabdomyolysis after donepezil use were not severe, and no patient was treated with acute dialysis or mechanical ventilation.

INTERPRETATION: Initiating donepezil is associated with a higher 30-day risk of admission to hospital with rhabdomyolysis compared with initiating rivastigmine or galantamine. The proportion of patients who develop severe rhabdomyolysis within 30 days of initiating donepezil is very low.

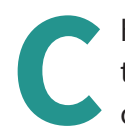

holinesterase inhibitors are the most common medications used to alleviate symptoms of Alzheimer disease and other dementias. Alzheimer disease is thought to be associated with central acetylcholine deficits, and donepezil is the leading acetylcholinesterase inhibitor used to treat the condition. ${ }^{1}$ In 2013, more than 2 million prescriptions for donepezil were dispensed in Canada., ${ }^{2,3}$ Rivastigmine and galantamine are 2 other commonly used cholinesterase inhibitors. Each drug has a different chemical structure but all inhibit the central breakdown of acetylcholine through reversible inhibition of cholinesterases. ${ }^{4-6}$ Donepezil is a piperidine derivative that is renally excreted. ${ }^{5}$ Rivastigmine is a carbamate derivative, renally excreted, that also inhibits butyrylcholinesterase. ${ }^{5,6}$ It is often considered "pseudoirreversible" owing to its long-acting inhibition. ${ }^{7}$ Galantamine is a phenanthrene alkaloid, hepatically excreted, and affects the regulation of nicotinic acetylcholine receptors., ${ }^{5,6}$
In January 2015, Health Canada issued a postmarket surveillance warning about a risk of rhabdomyolysis with donepezil use, based on 1 case report in Canada and 88 cases internationally. ${ }^{3}$ In original randomized controlled trials (RCTs) of donepezil, muscle cramps, but not rhabdomyolysis, were a mentioned adverse effect..$^{8-10}$ In February and July of 2015, respectively, the US Food and Drug Association and the European Medicines Agency recommended updated product monographs with a similar warning of rhabdomyolysis. ${ }^{11,12}$ The time interval of onset of rhabdomyolysis after donepezil use is unknown, although many of the case reports submitted to Health Canada comment that events occurred after the treatment was started or the dose increased. The Pharmacovigilance Databases of the United States and Canada showed that rhabdomyolysis was reported more often in patients using donepezil compared with other cholinesterase inhibitors (odds ratio [OR] 11.00, 95\% confidence interval [Cl] 10.39-27.41). ${ }^{13}$ There have been no published case reports of 
rhabdomyolysis associated with either rivastigmine or galantamine. ${ }^{14,15}$ One online review from the Pharmaceuticals and Medical Devices Agency of Japan suggests that a risk may be present with the latter of these 2 agents, but the report contains no cited references or expert statements to support the claim. ${ }^{16}$

We conducted this population-based cohort study to determine whether initiating donepezil is associated with a higher 30-day risk of hospital admission with rhabdomyolysis compared with rivastigmine or galantamine.

\section{Methods}

\section{Study design}

We conducted a population-based retrospective cohort study of older adults in Ontario, Canada, using linked health care databases through ICES. The province of Ontario has about 14 million residents, $16 \%$ (2.3 million) aged 65 years or older. ${ }^{17}$ Ontario residents have universal access to hospital care and physician services through a government-funded single-payer system, and older residents have universal outpatient prescription drug coverage. Reporting of this study follows guidelines for observational studies using routinely collected health care data (Supplemental Table 1, Appendix 1, available at www.cmaj.ca/lookup/suppl/doi:10.1503/cmaj.190337/-/DC1). ${ }^{18}$

\section{Data sources}

We ascertained patient characteristics, prescription drug dispensing and outcome data using records from large health care databases linked using unique, encoded identifiers. The Ontario Drug Benefit Database contains records of outpatient prescriptions dispensed to patients aged 65 years or older, with an error rate of less than $1 \% .{ }^{19}$ The Registered Persons Database has demographic and vital status information on all Ontario residents. The ICES Physician Database contains information on physician specialization and demographics. The Ontario Mental Health Reporting System houses information on mental health encounters. The Canadian Institute for Health Information (CIHI) Discharge Abstract Database has diagnosis and procedural information on all hospital admissions in Ontario. The Ontario Health Insurance Plan database contains billing claims for inpatient and outpatient physician services. The Ontario Laboratory Information System has laboratory measurements for a subpopulation of Ontario residents. We have previously used these population-based databases to research adverse drug events, including rhabdomyolysis. ${ }^{20-23}$

Databases were complete for all variables except rural location and income quintile, both with less than $0.5 \%$ missing, as well as prescriber information with missing data ranging from $11 \%$ to $18 \%$. The emigration rate from the province is low ( $0.5 \%$ per year) and is the only reason for lost follow-up. ${ }^{24}$ Based on $\mathrm{CIHI}$ guidelines, trained personnel in Ontario hospitals review medical charts to code diagnoses and procedures using the International Classification of Diseases (ICD) coding system. These personnel consider only physician-recorded diagnoses and do not review laboratory results. In this study, the codes used to assess baseline comorbidities are from the International Classification of Diseases, 9th Revision (ICD-9) and International Statistical Classification of Diseases and Related Health Problems, 10th Revision (ICD-10) (Supplemental
Table 2, Appendix 2, available at www.cmaj.ca/lookup/suppl/ doi:10.1503/cmaj.190337/-/DC1), while codes identifying a hospital admission with rhabdomyolysis (M628, T796) include only those from ICD-10, as events occurred after the implementation of this revision. To comply with privacy regulations, the exact number of participants was suppressed when there were 5 or fewer participants, and was reported as fewer than 6 .

\section{Patients}

We established a cohort of older adults in Ontario with a newly dispensed outpatient prescription for a study cholinesterase inhibitor (donepezil, rivastigmine or galantamine) between June 2002 and March 2017. All 3 drugs were available in Ontario's provincial drug formulary as of 2002. The dispensing date served as the start date for follow-up, also referred to as the index date. We excluded the following patients: i) those in their first year of eligibility of prescription drug coverage (those between age 65 and $66 \mathrm{yr}$ ) to avoid incomplete medication history; ii) those who had a dispensed prescription for donepezil, rivastigmine or galantamine in the 180 days before the index date, to ensure that patients were new users; iii) those with more than 1 cholinesterase inhibitor dispensed on the index date, to compare mutually exclusive groups; iv) those with end-stage renal disease; v) those discharged from hospital in the 2 days before the index date, to ensure these were new outpatient prescriptions; and vi) those with an invalid dose of cholinesterase inhibitor recorded in the database. If patients had more than 1 eligible prescription, the first was selected, and patients could enter the cohort only once.

Patients on rivastigmine or galantamine were considered together for a larger sample comparison group.

\section{Primary outcome}

We followed patients for 30 days after the index date, as the median (25th, 75th percentile) time of donepezil usage in our cohort was 30 days ( 15 to $30 \mathrm{~d}$ ). Additionally, a follow-up period of 30 days prevents crossovers between the groups, which could occur with a longer period. Lastly, the Health Canada warning indicates that most cases of rhabdomyolysis occurred after initiating or increasing the dose of donepezil. ${ }^{3}$ Our primary outcome was a hospital admission with rhabdomyolysis assessed with diagnostic codes. In our province, hospital admissions with rhabdomyolysis codes identified patients with a peak mean serum creatine kinase concentration of 7169 (standard deviation [SD] 36395) U/L during their stay in hospital. These codes have been used in other studies. ${ }^{20}$ As with other laboratory diagnostic codes, we expect them to show high specificity (> 99\%) but low sensitivity (sensitivity of hospital admission with acute kidney injury based on serum creatinine is $62 \%$; with hyperkalemia based on serum potassium is $14 \%$; and with hyponatremia based on serum sodium is $11 \%) .{ }^{25-27}$

\section{Additional analyses}

We performed several additional analyses, as well as descriptively examined characteristics of hospital admissions with rhabdomyolysis after donepezil use. First, we assessed the risk of hospital admission with rhabdomyolysis in patients dispensed donepezil versus a similar group of nonusers - patients with the same exclusion criteria, but no use of a cholinesterase inhibitor in the 
180 days before index date. We randomly assigned the index date (a phantom cholinesterase initiation date) to all patients in the nonuser group based on the distribution of prescription dates in the donepezil user group. While we would expect a higher chance of potential confounding with such a comparison, the results help address the theoretical concern that interpreting the risk with donepezil versus rivastigmine or galantamine is influenced if the latter protects against rhabdomyolysis. Second, similarly, we assessed the risk of hospital admission with rhabdomyolysis in patients dispensed either rivastigmine or galantamine, versus a similar group of nonusers: again, we randomly assigned the index date to the nonuser group based on the distribution of the prescription dates in the rivastigmine or galantamine group. Third, we compared the risk of rhabdomyolysis after donepezil use against that of patients initiating any statin, a well-known cause of drug-induced rhabdomyolysis; ${ }^{28-31}$ the comparison provides clinical context in which to interpret the risk of donepezil-induced rhabdomyolysis. For this analysis, the same inclusion and exclusion criteria were applied, but instead of a cholinesterase inhibitor, patients had a prescription for a statin that met the criteria, with no evidence of other statin use in the 180 days before the index date. Fourth, we assessed whether baseline statin use modified the association between donepezil versus rivastigmine or galantamine and the risk of rhabdomyolysis. In this analysis, we stratified individuals by baseline statin status, to examine potential interaction by concurrent statin usage. Given statins' independent association with rhabdomyolysis, we aimed to determine whether statin use increased the risk of rhabdomyolysis associated with donepezil use versus rivastigmine or galantamine. Finally, we evaluated the risk of hospital admission with bowel obstruction in users of donepezil versus rivastigmine or galantamine. This analysis was decided a priori as bowel obstruction was not expected to be associated with cholinesterase inhibitor type. We reasoned that a null association with this outcome would increase the credibility of any observed association with rhabdomyolysis. All additional analyses used the same selection criteria as our primary cohort, unless otherwise mentioned.

\section{Statistical analysis}

We compared baseline characteristics between users of donepezil to rivastigmine and galantamine using standardized differences. This measurement assesses differences between group means as a percentage of the pooled standard deviation, with a difference less than $10 \%$ considered negligible. ${ }^{32}$ We used logistic regression models to estimate odds ratios and 95\% confidence intervals. Odds ratios approximate relative risk when the event is rare (as for our outcome).

Using a logistic regression model, we derived a propensity score for the predicted probability of receiving a new prescription for donepezil versus rivastigmine or galantamine given a set of 83 baseline characteristics. As the rivastigmine and galantamine group was significantly smaller than the donepezil group, we elected to weight (rather than match) on the propensity score using inverse probability of treatment weights. We did use matching in several additional analyses when doing so did not result in a substantial loss of the study sample: i) users of donep- ezil versus nonusers of cholinesterase inhibitor; ii) users of rivastigmine and galantamine versus nonusers of cholinesterase inhibitor; and iii) users of donepezil versus those of statins. In these analyses, we matched 1:1 to the study drug users (donepezil, or rivastigmine or galantamine) on the logit of the propensity score $( \pm 0.2 \mathrm{SD})$ using a greedy matching algorithm without replacement. In each case, a new propensity score predicting the probability of receiving the study drug of interest was created.

\section{Ethics approval}

Data usage was authorized under section 45 of Ontario's Personal Health Information Protection Act, which does not require review by a research ethics board.

\section{Results}

The cohort selection is presented in Figure 1. After exclusions, we identified 220353 patients with a new dispensed prescription for donepezil ( $n=152300)$, or rivastigmine or galantamine ( $n=$ 68053 ). The baseline characteristics of the 2 groups without any statistical method of adjustment were nearly identical. Select baseline characteristics are presented in Table 1 (full data presented in Supplemental Table 3, Appendix 3, available at www. cmaj.ca/lookup/suppl/doi:10.1503/cmaj.190337/-/DC1).

Results of the primary outcome are presented in Table 2. Donepezil was associated with a small but statistically significant higher risk of hospital admission with rhabdomyolysis compared with rivastigmine or galantamine (88 events in 152300 patients [0.06\%] v. 16 events in 68053 patients [0.02\%]; weighted odds ratio of $2.21,95 \% \mathrm{Cl} 1.52$ to 3.22 ).

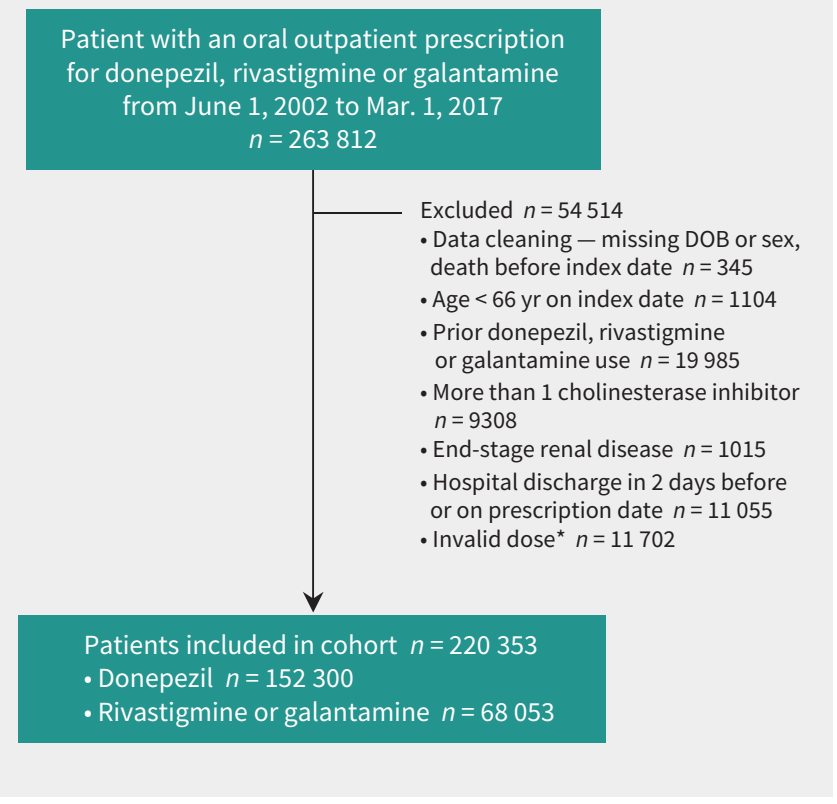

Figure 1: Cohort selection. *Valid doses were $2.5-25.5 \mathrm{mg} / \mathrm{d}$ for donepezil, $1.5-13.5 \mathrm{mg} / \mathrm{d}$ for rivastigmine, and $2-26 \mathrm{mg} / \mathrm{d}$ for galantamine. This was based on half the initial recommended dose to half of the smallest tab available, added to the maximum recommended dose (e.g., the recommendations for donepezil are $5-23 \mathrm{mg} / \mathrm{d}$ ). Note: $\mathrm{DOB}=$ date of birth. 
Table 1 (part 1 of 2): Select baseline characteristics

\begin{tabular}{|c|c|c|c|c|c|c|}
\hline \multirow[b]{2}{*}{ Characteristic } & \multicolumn{3}{|c|}{ Unweighted } & \multicolumn{3}{|c|}{ Weighted $^{\star}$} \\
\hline & $\begin{array}{c}\text { Donepezil, no. }(\%) \dagger \\
n=152300\end{array}$ & $\begin{array}{c}\text { Rivastigmine or } \\
\text { galantamine, no. }(\%) \dagger \\
n=68053\end{array}$ & $\begin{array}{l}\text { Standardized } \\
\text { difference, \%¥ }\end{array}$ & $\begin{array}{c}\text { Donepezil, no. }(\%) \dagger \\
n=152300\end{array}$ & $\begin{array}{c}\text { Rivastigmine or } \\
\text { galantamine, no. }(\%) \dagger \\
n=152161\end{array}$ & $\begin{array}{l}\text { Standardized } \\
\text { difference, \%‡ }\end{array}$ \\
\hline \multicolumn{7}{|l|}{ Demographics } \\
\hline Age, yr, mean \pm SD & $81.2 \pm 6.6$ & $80.9 \pm 6.6$ & 5 & $81.2 \pm 6.6$ & $81.2 \pm 10.0$ & 0 \\
\hline Women & $94254(61.9)$ & $40956(60.2)$ & 3 & 94254 (61.9) & $94122(61.9)$ & 0 \\
\hline \multicolumn{7}{|l|}{ Year of cohort entry } \\
\hline $2002-2004$ & $25908(17.0)$ & $13863(20.4)$ & 9 & $25908(17.0)$ & $25502(16.8)$ & 1 \\
\hline $2005-2007$ & $27767(18.2)$ & $17274(25.5)$ & 18 & $27767(18.2)$ & $27756(18.2)$ & 0 \\
\hline $2008-2010$ & $30605(20.1)$ & $18487(27.2)$ & 17 & $30605(20.1)$ & $30830(20.3)$ & 0 \\
\hline 2011-2013 & $34771(22.8)$ & $10245(15.0)$ & 20 & $34771(22.8)$ & $34998(23.0)$ & 0 \\
\hline 2014-2017 & $33249(21.9)$ & $8184(12.0)$ & 27 & $33249(21.9)$ & $22547(14.8)$ & 0 \\
\hline Long-term care & $15415(10.1)$ & $9813(14.4)$ & 13 & $15415(10.1)$ & $18266(12.0)$ & 6 \\
\hline Rural & $20046(13.2)$ & 7489 (11.0) & 7 & $20046(13.2)$ & $20535(13.5)$ & 1 \\
\hline \multicolumn{7}{|l|}{ Income quintile } \\
\hline 1 (lowest) & $30579(20.1)$ & $14245(20.9)$ & 2 & $30579(20.1)$ & $30669(20.2)$ & 0 \\
\hline 2 & $31615(20.8)$ & $14313(21.0)$ & 0 & $31615(20.8)$ & $31637(20.8)$ & 0 \\
\hline 3 & $29899(19.6)$ & $13257(19.5)$ & 0 & $29899(19.6)$ & $30257(19.9)$ & 1 \\
\hline 4 & $30038(19.7)$ & $13104(19.3)$ & 1 & $30038(19.7)$ & $30110(19.8)$ & 0 \\
\hline 5 (highest) & $29641(19.5)$ & $12891(18.9)$ & 2 & $29641(19.5)$ & $29488(19.4)$ & 0 \\
\hline \multicolumn{7}{|l|}{ Comorbidity } \\
\hline Atrial fibrillation & $12961(8.5)$ & $6113(9.0)$ & 2 & $12961(8.5)$ & $12953(8.5)$ & 0 \\
\hline $\begin{array}{l}\text { Coronary artery } \\
\text { disease }\end{array}$ & $43339(28.5)$ & $21600(31.7)$ & 7 & $43339(28.5)$ & $43265(28.4)$ & 0 \\
\hline Chronic liver disease & $4071(2.7)$ & $1928(2.8)$ & 1 & $4071(2.7)$ & $4020(2.6)$ & 0 \\
\hline Chronic lung disease & $36418(23.9)$ & $17082(25.1)$ & 3 & $36418(23.9)$ & $36307(23.9)$ & 0 \\
\hline $\begin{array}{l}\text { Chronic kidney } \\
\text { disease }\end{array}$ & $12089(7.9)$ & $5505(8.1)$ & 1 & $12089(7.9)$ & $12188(8.0)$ & 0 \\
\hline Depression & $21834(14.3)$ & $11121(16.3)$ & 6 & $21834(14.3)$ & $21905(14.4)$ & 0 \\
\hline Diabetes mellitus & $25056(16.5)$ & $11570(17.0)$ & 1 & $25056(16.5)$ & $25094(16.5)$ & 0 \\
\hline Heart failure & $22811(15.0)$ & $11349(16.7)$ & 5 & $22811(15.0)$ & $22863(15.0)$ & 0 \\
\hline Parkinson disease & $7710(5.1)$ & $5660(8.3)$ & 13 & $7710(5.1)$ & $8022(5.3)$ & 1 \\
\hline $\begin{array}{l}\text { Peripheral vascular } \\
\text { disease }\end{array}$ & $2495(1.6)$ & $1228(1.8)$ & 2 & $2495(1.6)$ & $2487(1.6)$ & 0 \\
\hline Seizure disorder & $1505(1.0)$ & 787 (1.2) & 2 & $1505(1.0)$ & $1492(1.0)$ & 0 \\
\hline Sepsis & $1889(1.2)$ & 894 (1.3) & 1 & $1889(1.2)$ & $1929(1.3)$ & 0 \\
\hline Stroke & $7629(5.0)$ & $4315(6.3)$ & 6 & $7629(5.0)$ & $7688(5.1)$ & 0 \\
\hline \multicolumn{7}{|c|}{ Prescribing physician characteristic } \\
\hline \multicolumn{7}{|l|}{ Specialty } \\
\hline Cardiology & $351(0.2)$ & $87(0.1)$ & 3 & $351(0.2)$ & $170(0.1)$ & 2 \\
\hline General practice & $97325(63.9)$ & $40176(59.0)$ & 10 & $97325(63.9)$ & $91886(60.4)$ & 7 \\
\hline Geriatric medicine & $18764(12.3)$ & $10371(15.2)$ & 8 & $18764(12.3)$ & $23848(15.7)$ & 10 \\
\hline Nephrology & $86(0.1)$ & $47(0.1)$ & 0 & $86(0.1)$ & $107(0.1)$ & 1 \\
\hline Neurology & $8565(5.6)$ & $4312(6.3)$ & 3 & $8565(5.6)$ & $8879(5.8)$ & 1 \\
\hline Other & $10387(6.8)$ & $5394(7.9)$ & 1 & $10387(6.8)$ & $11469(7.5)$ & 3 \\
\hline Rural practice & $14456(9.5)$ & $4970(7.3)$ & 8 & $14456(9.5)$ & $12943(8.5)$ & 3 \\
\hline ACE inhibitors & $43752(28.7)$ & $21012(30.9)$ & 5 & $43752(28.7)$ & $43906(28.9)$ & 0 \\
\hline
\end{tabular}


Table 1 (part 2 of 2): Select baseline characteristics

\begin{tabular}{|c|c|c|c|c|c|c|}
\hline \multirow[b]{2}{*}{ Characteristic } & \multicolumn{3}{|c|}{ Unweighted } & \multicolumn{3}{|c|}{ Weighted ${ }^{\star}$} \\
\hline & $\begin{array}{c}\text { Donepezil, no. }(\%) \dagger \\
n=152300\end{array}$ & $\begin{array}{c}\text { Rivastigmine or } \\
\text { galantamine, no. }(\%) \dagger \\
n=68053\end{array}$ & $\begin{array}{l}\text { Standardized } \\
\text { difference, \%‡ }\end{array}$ & $\begin{array}{c}\text { Donepezil, no. (\%)† } \\
n=152300\end{array}$ & $\begin{array}{c}\text { Rivastigmine or } \\
\text { galantamine, no. }(\%) \dagger \\
n=152161\end{array}$ & $\begin{array}{l}\text { Standardized } \\
\text { difference, \%‡ }\end{array}$ \\
\hline $\begin{array}{l}\text { Angiotensin receptor } \\
\text { blockers }\end{array}$ & $18042(11.8)$ & 7975 (11.7) & 0 & $18042(11.8)$ & $17918(11.8)$ & 0 \\
\hline Antidepressants & 40251 (26.4) & $20102(29.5)$ & 7 & 40251 (26.4) & $40630(26.7)$ & 1 \\
\hline Antiepileptics & $6417(4.2)$ & $2902(4.3)$ & 0 & $6417(4.2)$ & $6430(4.2)$ & 0 \\
\hline Antipsychotics & $15559(10.2)$ & 9798 (14.4) & 13 & $15559(10.2)$ & $15807(10.4)$ & 0 \\
\hline$\beta$-blockers & 39857 (26.2) & $18794(27.6)$ & 3 & $39857(26.2)$ & $39717(26.1)$ & 0 \\
\hline $\begin{array}{l}\text { Calcium channel } \\
\text { blockers }\end{array}$ & $38049(25.0)$ & $17485(25.7)$ & 2 & $38049(25.0)$ & $37863(24.9)$ & 0 \\
\hline Colchicine & $45(0.0)$ & $16(0.0)$ & 1 & $45(0.0)$ & $39(0.0)$ & 0 \\
\hline Fibrates & $1912(1.3)$ & $958(1.4)$ & 1 & $1912(1.3)$ & $1918(1.3)$ & 0 \\
\hline Diuretics & 39977 (26.2) & $18700(27.5)$ & 3 & 39977 (26.2) & $39962(26.3)$ & 0 \\
\hline $\begin{array}{l}\text { Histamine-2 receptor } \\
\text { antagonist }\end{array}$ & $8610(5.7)$ & $4530(6.7)$ & 4 & $8610(5.7)$ & $8562(5.6)$ & 0 \\
\hline Statins & $60433(39.7)$ & $27197(40.0)$ & 1 & $60433(39.7)$ & $60366(39.7)$ & 0 \\
\hline
\end{tabular}

Table 2: Primary outcome analysis: hospital admission with rhabdomyolysis

\section{Unweighted}

Exposure

$88 / 152300(0.06)$

$16 / 68053(0.02)$

Rivastigmine or

galantamine

Events, no. (\%)

OR $(95 \% \mathrm{CI})$
$2.46(1.44-4.19)$
Referent

Referent

Note: $\mathrm{Cl}=$ confidence interval, $\mathrm{OR}=$ odds ratio.

*Weighted events are not true event rates in the rivastigmine or galantamine group, but frequencies based on weighted analysis.
Weighted

\begin{tabular}{|cc}
\hline Events, ${ }^{*}$ no. (\%) & OR $(\mathbf{9 5 \% ~ C l )}$ \\
\hline $88 / 152300(0.06)$ & $2.21(1.52-3.22)$ \\
\hline $39.78 / 152161(0.03)$ & Referent
\end{tabular}

39.78/152 $161(0.03) \quad$ Referent

\section{Additional analyses}

In the 88 donepezil users who were admitted to hospital with rhabdomyolysis, the median (25th, 75th percentile) length of hospital stay was 12 days ( 8 to 22.5). Fewer than 6 patients died during their stay in hospital. Nine patients $(10 \%)$ were admitted to the intensive care unit, although none of the 88 donepezil users received mechanical ventilation, nor acute dialysis.

In patients dispensed donepezil compared with a similar cohort of nonusers, donepezil was associated with a higher risk of hospital admission with rhabdomyolysis (72 [0.06\%] v. 44 [0.03\%] events, respectively; OR 1.64, 95\% Cl 1.13-2.38) (Supplemental Table 4, Appendix 4, available at www.cmaj.ca/lookup/ suppl/doi:10.1503/cmaj.190337/-/DC1). In patients dispensed rivastigmine or galantamine compared with a similar cohort of nonusers, there was no difference in the risk of hospital admission with rhabdomyolysis (16 [0.03\%] v. 29 [0.05\%] events, respec- tively; OR $0.55,95 \% \mathrm{Cl} 0.30$ to 1.02 ) (Supplemental Table 5, Appendix 5, available at www.cmaj.ca/lookup/suppl/doi:10.1503 /cmaj.190337/-/DC1).

The risk of hospital admission with rhabdomyolysis in new users of donepezil versus new users of statins was not statistically different (37 [0.05\%] v. 47 [0.06\%] events, respectively; OR 0.79, 95\% Cl 0.51-1.21) (Supplemental Table 6, Appendix 6, available at www.cmaj.ca/lookup/suppl/doi:10.1503/cmaj.190337/-/DC1).

There was no evidence that baseline statin use modified the observed association between donepezil versus rivastigmine or galantamine and the risk of rhabdomyolysis ( $p$ value for interaction 0.28) (Supplemental Table 7, Appendix 7, available at www. cmaj.ca/lookup/suppl/doi:10.1503/cmaj.190337/-/DC1).

A significant difference in hospital admission with bowel obstruction between users of donepezil and users of rivastigmine or galantamine was neither expected nor observed $(85$ [0.06\%] 
v. 46 [0.07\%] events, respectively; adjusted OR 0.85, 95\% CI 0.591.23) (Supplemental Table 8, Appendix 8, available at www.cmaj. ca/lookup/suppl/doi:10.1503/cmaj.190337/-/DC1).

\section{Interpretation}

Dementia is a common problem in our aging society, with almost 10 million patients given a new diagnosis worldwide each year. ${ }^{33}$ Safety concerns have been raised regarding the risk of rhabdomyolysis with donepezil, the leading acetylcholinesterase inhibitor used to treat dementia. Overall, there is a paucity of literature on this risk. In this study we aimed to better characterize the risk of donepezil-related rhabdomyolysis. Compared with rivastigmine or galantamine, in relative terms, donepezil was associated with a 2-fold higher risk of hospital admission with rhabdomyolysis.

The biological mechanism of donepezil-associated rhabdomyolysis is unknown. Acetylcholine is known to play a role in action potential transmission across the neuromuscular junction, leading to muscle contraction..$^{34}$ Theoretically, preventing the breakdown of acetylcholine may lead to abnormalities in muscle contraction and ultimately rhabdomyolysis. This area warrants further research.

The 30-day incidence of hospital admission with rhabdomyolysis for patients initiated on donepezil was 6 in 10000 prescriptions $(0.06 \%)$, or about 1 in every 1667 prescriptions. As shown with other laboratory-based diagnoses, ${ }^{25,26}$ we expect that diagnosis codes underestimate the true incidence of rhabdomyolysis, particularly when one considers milder forms of the condition or cases in which the patient was not admitted to hospital. The magnitude of this underestimation is uncertain. However, if one assumed that the diagnostic codes underestimate true incidence by 10 -fold, there would still be only 1 more hospital admission with rhabdomyolysis for every 300 patients initiated on donepezil, compared with other cholinesterase inhibitors.

If patients on donepezil describe symptoms of muscle cramping, it would be prudent to consider a diagnosis of rhabdomyolysis and measure creatine kinase levels. Fortunately, in our analysis, hospital admissions with rhabdomyolysis were not extreme in their severity. In patients at high risk of rhabdomyolysis, including a prior history of the condition, it may be reasonable to initiate a different cholinesterase inhibitor.

Statin-induced rhabdomyolysis is a well-recognized adverse drug event..$^{28-31}$ The risk of hospital admission with rhabdomyolysis was not significantly different between new users of donepezil compared with any type of statin, which may help put our results into clinical context. We did not find that coprescription of a statin and donepezil heightened risk of rhabdomyolysis, while we appreciate that our analysis had adequate statistical power only to detect a large interaction. All statins were assessed together. There are differences in metabolism depending on the statin that may increase risk of rhabdomyolysis, which may have limited the interpretation of these results.

Our study has several strengths. Our sample size of more than 150000 donepezil users provided the opportunity to study an uncommon but important adverse event. In our primary analysis, there was a marked similarity of measured baseline characteristics in the 2 groups of cholinesterase inhibitor users, reducing concerns that the observed association with rhabdomyolysis was confounded. Our findings proved robust in several additional analyses.

\section{Limitations}

There are several limitations to our study. First, this is a retrospective cohort study using administrative health care databases, without information on medication adherence or patient symptoms. All observational studies remain subject to concerns about residual confounding. Second, we could not accurately capture falls in our administrative data, which is another common reason for rhabdomyolysis in older patients. ${ }^{35}$ Third, as only adults older than 65 years were included in our study, the results may not be generalizable to dementia in younger adults, which can be more variable and secondary to other comorbidities. ${ }^{36}$ Next, we excluded patients with doses outside recommended routine prescribing practices. There may be additional risks if patients take a dose higher than that recommended. Fifth, while rivastigmine and galantamine have different mechanisms of action, they were considered together for reasons of sample size, given the rarity of the outcome. With the medications combined, there are still only 16 events in our follow-up. To comply with privacy regulations for minimizing the chance of identification of a study patient, at ICES numbers of patients are suppressed in the case of 5 or fewer patients (reported as fewer than 6), so reporting the results of the 2 medications separately was not meaningful. This limits conclusions about either drug separately, although no published studies provide data to support a risk of rhabdomyolysis with either of these medications. Lastly, creatine kinase levels were not available for most of our cohort, and only rhabdomyolysis events associated with a hospital admission were considered; therefore, less severe cases of rhabdomyolysis may have been missed.

\section{Conclusion}

The findings of this population-based cohort study support regulatory agency warnings about the risk of donepezil-induced rhabdomyolysis. Reassuringly, the 30-day incidence of a hospital admission with rhabdomyolysis after initiating donepezil remains low.

\section{References}

1. Cacabelos R. Donepezil in Alzheimer's disease: from conventional trials to pharmacogenetics. Neuropsychiatr Dis Treat 2007;3:303-33.

2. Lee PE, Hsiung G-YR, Seitz D, et al. Cholinesterase inhibitors. BCMJ 2011;53:404-8.

3. Alzheimer's drug Aricept (donepezil) - New warnings on the serious risks of muscle breakdown and of a neurological disorder. Ottawa: Health Canada; 2015. Available: http://healthycanadians.gc.ca/recall-alert-rappel-avis/hc-sc /2015/43469a-eng.php (accessed 2017 July 29).

4. Čolović MB, Krstić DZ, Lazarević-Pašti TD, et al. Acetylcholinesterase inhibitors: pharmacology and toxicology. Curr Neuropharmacol 2013;11:315-35.

5. Wishart DS, Feunang YD, Guo AC, et al. DrugBank 5.0: a major update to the DrugBank database for 2018. Nucleic Acids Res 2018;46:D1074-82.

6. Fisher A, Carney G, Bassett K, et al. Tolerability of cholinesterase inhibitors: a population-based study of persistence, adherence, and switching. Drugs Aging 2017;34:221-31.

7. Jann MW. Rivastigmine, a new-generation cholinesterase inhibitor for the treatment of Alzheimer's disease. Pharmacotherapy 2000;20:1-12.

8. Rogers SL, Farlow MR, Doody RS, et al. A 24-week, double-blind, placebo-controlled trial of donepezil in patients with Alzheimer's disease. Donepezil Study Group. Neurology 1998;50:136-45. 
9. Birks JS, Harvey RJ. Donepezil for dementia due to Alzheimer's disease. Cochrane Database Syst Rev 2018;6:CD001190.

10. Birks J. Cholinesterase inhibitors for Alzheimer's disease. Cochrane Database Syst Rev 2006;(1):CD005593.

11. Hughes A. Supplemental approval. Silver Springs (MD): US Food and Drug Administration; 2015. Available: www.accessdata.fda.gov/drugsatfda_docs/appletter /2015/0225680rig1s008,0217200rig1s012,0206900rig1s039ltr.pdf (accessed 2017 Dec. 8).

12. Pharmacovigilance Risk Assessment Committee. New product information wording - Extracts from PRAC recommendations on signals. London (UK): European Medicines Agency; 2015. Available: www.ema.europa.eu/docs/en GB/document_library/Other/2015/08/WC500191719.pdf (accessed 2018 Dec. 3).

13. Ali TB, Schleret TR, Reilly BM, et al. Adverse effects of cholinesterase inhibitors in dementia, according to the pharmacovigilance databases of the UnitedStates and Canada. PLoS One 2015;10:e0144337.

14. Highlights of prescribing information: RAZADYNE ER and RAZADYNE. Beerse (Belgium): Janssen Pharmaceuticals, Inc.; 2013. Available: www.janssenlabels.com/ package-insert/product-monograph/prescribing-information/RAZADYNE+ER-pi .pdf (accessed 2018 Jan. 14).

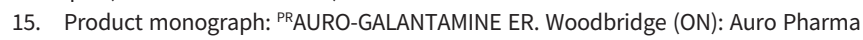
Inc.; revised 2017 Nov. 29. Available: http://auropharma.ca/products/monograph /Auro-Galantamine-PM.pdf (accessed 2018 Jan. 14).

16. Summary of investigation results: galantamine hydrobromide. Tokyo (Japan): Pharmaceuticals and Medical Devices Agency; 2015. Available: www.pmda.go.jp/ files/000207919.pdf (accessed 2018 Jan. 14).

17. Table 17-10-0005-01: Population estimates on July 1st, by age and sex. Ottawa: Statistics Canada: modified 2019 July 19. Available: https://www150. statcan.gc.ca/t1/tbl1/en/tv.action?pid=1710000501 (accessed 2017 Jan. 22).

18. Benchimol El, Smeeth L, Guttmann A, et al.; RECORD Working Committee. The REporting of studies Conducted using Observational Routinely-collected health Data (RECORD) statement. PLoS Med 2015;12:e1001885.

19. Levy AR, O'Brien BJ, Sellors C, et al. Coding accuracy of administrative drug claims in the Ontario Drug Benefit database. Can J Clin Pharmacol 2003;10:67-71.

20. Patel AM, Shariff S, Bailey DG, et al. Statin toxicity from macrolide antibiotic coprescription: a population-based cohort study. Ann Intern Med 2013;158:869-76.

21. Li DQ, Kim RB, McArthur E, et al. Statin safety in Chinese: a population-based study of older adults. PLOS One 2016;11:e0150990.

22. Li DQ, Kim R, McArthur E, et al. Risk of adverse events among older adults fol- lowing co-prescription of clarithromycin and statins not metabolized by cytochrome P450 3A4. CMAJ 2015;187:174-80.

23. Welk B, McArthur E, Ordon M, et al. Risk of rhabdomyolysis from 5 - $\alpha$ reductase inhibitors. Pharmacoepidemiol Drug Saf 2018;27:351-5.

24. Willbond S. Migration: interprovincial, 2011/2012. Ottawa: Statistics Canada; modified 2015 Nov 30. Available: www150.statcan.gc.ca/n1/pub/91-209-x/2014001/ article/14012-eng.htm (accessed 2018 Feb. 12).

25. Hwang YJ, Shariff SZ, Gandhi S, et al. Validity of the International Classification of Diseases, Tenth Revision code for acute kidney injury in elderly patients at presentation to the emergency department and at hospital admission. BMJ Open 2012;2:e001821.

26. Fleet JL, Dixon SN, Shariff SZ, et al. Detecting chronic kidney disease in population-based administrative databases using an algorithm of hospital encounter and physician claim codes. BMC Nephrol 2013;14:81.

27. Fleet JL, Shariff SZ, Gandhi S, et al. Validity of the International Classification of Diseases 10th revision code for hyperkalaemia in elderly patients at presentation to an emergency department and at hospital admission. BMJ Open 2012;2:e002011.

28. Mendes P, Robles PG, Mathur S. Statin-induced rhabdomyolysis: a comprehensive review of case reports. Physiother Can 2014;66:124-32.

29. Schreiber DH, Anderson TR. Statin-induced rhabdomyolysis. J Emerg Med 2006;31:177-80.

30. Thompson PD, Clarkson P, Karas RH. Statin-associated myopathy. JAMA 2003;289:1681-90.

31. Wooltorton E. Rosuvastatin (Crestor) and rhabdomyolysis. CMAJ 2004;171:129.

32. Austin PC. Using the standardized difference to compare the prevalence of a binary variable between two groups in observational research. Commun Stat Simul Comput 2009;38:1228-34. doi: 10.1080/03610910902859574.

33. The epidemiology and impact of dementia: current state and future trends. Geneva: World Health Organization; 2015. Available: www.who.int/mental_health/ neurology/dementia/dementia_thematicbrief_epidemiology.pdf (accessed 2017 July 25).

34. Martyn JA, Fagerlund MJ, Eriksson LI. Basic principles of neuromuscular transmission. Anaesthesia 2009;64(Suppl 1):1-9.

35. Wongrakpanich S, Kallis C, Prasad P, et al. The study of rhabdomyolysis in the elderly: an epidemiological study and single center experience. Aging Dis 2018;9:1-7.

36. Beattie AM, Daker-White G, Gilliard J, et al. Younger people in dementia care: a review of service needs, service provision and models of good practice. Aging Ment Health 2002;6:205-12.

\section{Competing interests: None declared.}

This article has been peer reviewed.

Affiliations: Department of Physical Medicine and Rehabilitation (Fleet), McMaster University, Hamilton, Ont.; ICES (Fleet, McArthur, Weir, Garg); Divisions of Nephrology (Patel, Weir, Garg) and Geriatrics (MonteroOdasso), Departments of Medicine and Epidemiology \& Biostatistics (Montero-Odasso, Garg), Western University, London, Ont.

Contributors: Jamie Fleet and Amit Garg developed the initial study plan. Jamie Fleet performed initial literature review. Eric McArthur and Amit Garg contributed to the study and analysis plan. Eric McArthur completed all statistical analyses. All authors interpreted the results. Jamie Fleet drafted the initial manuscript and all other authors revised it critically for important intellectual content, gave final approval of the version to be published and agreed to be accountable for all aspects of the work.

Funding: Amit Garg was supported by the Dr. Adam Linton Chair in Kidney Health Analytics and a Clinician Investigator Award from the Canadian Institutes of Health Research (CIHR).

Data sharing: The data set from this study is held securely in coded form at ICES. While data sharing-agreements prohibit ICES from making the data set publicly available, access can be granted to those who meet prespecified criteria for confidential access, available at www.ices.on.ca/DAS
Acknowledgements: The authors thank IMS Brogan Inc. for use of their Drug Information Database. Parts of this material are based on data and information compiled and provided by the Canadian Institutes of Health Information (CIHI). However, the analyses, conclusions, opinions and statements expressed herein are those of the authors, and not necessarily those of CIHI.

Disclaimer: This study was supported by ICES, which is funded by an annual grant from the Ontario Ministry of Health and Long-Term Care (MOHLTC). Core funding for ICES Western is provided by the Academic Medical Organization of Southwestern Ontario (AMOSO), the Schulich School of Medicine and Dentistry (SSMD), Western University, and the Lawson Health Research Institute (LHRI). The research was conducted by members of the ICES Kidney, Dialysis and Transplantation team, at the ICES Western facility, who are supported by a grant from CIHR. Grant funding for this project was through an AMOSO Innovation Fund grant titled "Population-based studies to understand the side effects of medications in the brain-kidney axis." The opinions, results and conclusions are those of the authors and are independent from the funding sources. No endorsement by ICES, AMOSO, SSMD, LHRI, CIHR, or the Ontario MOHLTC is intended or should be inferred.

Accepted: July 22, 2019

Correspondence to: Jamie Fleet, Jamie.fleet@medportal.ca 